\title{
Aislamiento de bacterias degradadoras de pesticidas organofosforados encontrados en suelos $y$ en leche bovina
}

\author{
Isolation of organophosphorus pesticides \\ degrading bacteria found in \\ soil and bovine milk
}

\begin{abstract}
The increasing use of organophosphorus pesticides in agricultural practices over the past few years has generated a number of environmental problems; these compounds tend to bioaccumulate through food chains showing high levels of toxicity triggering potential health risk for species that are exposed to these substances. In this research were used the Soxhlet and solid phase micro extraction in headspace (HS-SPME) methods for the extraction of organophosphorus pesticides in agricultural cattle soils and bovine milk, respectively. The presence of demeton-Smethylsulfon was determined at concentrations between 272.9 and 1793.3 ppm in cropland and 12.9 ppm in cow milk. Native soil bacteria were isolated showing degrading capacity of these pesticides, Bacillus sp and Pantoea agglomerans which gave results of degradation of $73.5 \%$ and $68.6 \%$, respectively, in the concentration of chlorpyrifos, showing that these microorganisms are a possible solution for improving soils contaminated by this class of pesticides.

Key words: Bacillus sp, pantoea agglomerans, HS-SPME, chlorpyrifos, demethon-S-methylsulphon, cow milk.
\end{abstract}

\section{INTRODUCCIÓN}

El nuevo entorno mundial del comercio de alimentos obliga a los países importadores como a los exportadores a reforzar sus sistemas de control de los alimentos. Esto conlleva adoptar, hacer y observar estrategias de control de los alimentos basadas en el riesgo en vigilancia sanitaria y de inocuidad alimentaria. De acuerdo con los organismos mundiales de referencia, los residuos de fármacos y agroquímicos en alimentos de origen animal son considerados un factor de riesgo en la salud pública y como limitante en el desarrollo económico de cualquier país (1) (FAO/OMS, 2003).

Los estudios sobre la presencia de residuos de plaguicidas en la cadena alimentaria de leche de ganado vacuno se han centrado, fundamentalmente, en la presencia de pesticidas organoclorados por su alta persistencia y liposolubilidad (2-5). Pero su progresivo desuso a favor de compuestos organofosforados motiva que se planteen estudios sobre contenido residual de ellos (6-10). Las causas principales de la presencia de residuos de plaguicidas organofosforados (OF) en leche son sus propiedades fisicoquímicas particulares de liposolubilidad.
Luis Fernando Marín L. (1) Beatriz Jaramillo C. (2)

(1) Universidad de Cartagena, Facultad de Ciencias Exactas, Programa de Química, Grupo de Investigaciones Agroquímicas. Cartagena de Indias, Colombia.

(2) Grupo de Investigaciones Agroquímicas. Sede San Pablo, Facultad de Ciencias Exactas y Naturales, Universidad de Cartagena, Cartagena de Indias, Colombia.

Dirigir la correspondencia a:

Doctora

Beatriz Eugenia Jaramillo Colorado, Ph.D Grupo de Investigaciones Agroquímicas Programa de Química Facultad de Ciencias Exactas y Naturales, Sede San Pablo.

Universidad de Cartagena Cartagena, Colombia

Teléfono: 57-5-6600676 Fax: 57-5-6600676

E-mail: bjaramilloc@unicartagena.edu.co, beatrizjaramilloc@yahoo.com

Este trabajo fue recibido el 23 de Septiembre de 2014 y aceptado para ser publicado el 10 de Abril de 2015.

Además, se debe mencionar el uso excesivo y poco regulado de estos compuestos en las prácticas agropecuarias para el control de las enfermedades de los animales, transmitidas por insectos y parásitos $(8,9)$. Se ha comprobado que los animales productores de leche expuestos a tales condiciones son capaces de trasladar a su proceso metabólico compuestos plaguicidas y pueden ser acumulados en lípidos y lipoproteínas. Debido al porcentaje de grasa presente en la leche, ésta se convierte en un medio, en el cual es de esperarse la presencia de residuos de plaguicidas organofosforados o de algún metabolito de biotransformación de éste (10-12).

Los compuestos organofosforados constituyen un grupo heterogéneo con estructuras químicas derivadas del ácido fosfórico, específicamente son ésteres de este ácido. Entre sus principales propiedades fisicoquímicas encontramos que son mayormente liposolubles y medianamente volátiles, lo que le permite a este grupo de plaguicidas presentar altos niveles de toxicidad y bioacumulación en las cadenas tróficas, por lo que a nivel mundial se han realizado estudios exhaustivos de sus propiedades tóxicas y la capacidad de afección en los seres 
vivos que no son su objetivo, ya sea de manera directa en los animales, tales como el ganado, para el control de plagas y de forma indirecta para el hombre por medio del consumo de alimentos que han sido tratados por estos compuestos de tipo OPs (12-15).

Las características de estos compuestos han permitido que se utilicen diversos métodos para su extracción en las diferentes matrices existentes, los cuales, se caracterizan por sus eficientes resultados debido al permanente contacto con la muestra, entre ellos está la extracción soxhlet (16). La micro extracción en fase sólida en el espacio de cabeza (HS-SPME) constituye un método eficaz de extracción ya que reduce los costos de solvente, tiempo y es aplicable a todo tipo de muestras $(8,11)$, además, ha mostrado excelentes resultados en la extracción de pesticidas en todas las matrices (17-21).

En Colombia, el municipio de San Bernardo Del Viento por estar ubicado en el departamento de Córdoba, en una zona de trópico bajo y según el Ministerio de Agricultura, Protección Social y de Ambiente, es apta para el ejercicio de actividades agropecuarias, por lo tanto, no está exento del uso de este tipo de compuestos (OPs). San Bernardo del Viento comprende una extensa zona propicia para el desarrollo de la ganadería y cultivos agrícolas, de los que resaltan el arroz, maíz, ñame, yuca, plátano y coco. A su vez, por ser un municipio que presenta un grado bajo de tecnificación y una mano de obra no calificada. Los campesinos del sector realizan sus actividades de manera artesanal, principalmente, al momento de controlar todo tipo de plagas, mediante el uso de pesticidas sin la supervisión de personas expertas, sino bajo criterio propio, lo que estaría generando un desequilibrio ambiental y de salud pública por el uso de estos compuestos (22).

Estudios en diversos países como México y Polonia han demostrado que la biorremediación de pesticidas organofosforados por medio de microorganismos aislados de suelos agrícolas ha tenido grandes resultados, mostrando degradaciones de hasta un $98 \%(14,23)$. En nuestro país trabajos realizados por la compañía de petróleo Ecopetrol han reportado que la biorremediación es una herramienta útil para eliminación de hidrocarburos en diferentes matrices, reduciendo el impacto ambiental producido por este tipo de compuestos (24).

Estos estudios posibilitan la aplicación de esta técnica en los suelos de cultivo del municipio de San Bernardo Del Viento mediante el aislamiento de cepas bacterianas nativas de los suelos cultivados, y que a su vez posean capacidad degradadora de pesticidas organofosforados, ya que dichos compuestos poseen una dinámica ambiental de tal manera que pueden migrar de una matriz como los suelos a otra como lo la leche de ganado bovino. Esto es debido, posiblemente, a la acción de prácticas agrícolas como el pastoreo en zonas expuestas a este tipo de sustancias lo que permite encontrarlas en un rango de concentraciones variadas en cada una de las diferentes matrices ambientales.

Los objetivos de este trabajo fueron determinar pesticidas organofosforados (OP's) en suelos y en leche de vaca del municipio de San Bernardo del Viento y además, aislar bacterias degradadoras de este tipo de contaminantes fosforados de los suelos recolectados.

\section{MATERIALES Y MÉTODOS}

Obtención de muestras de suelo. Las muestras de suelos y leche cruda de vaca, se recolectaron en una finca agrícola y ganadera del municipio de San Bernardo del Viento, departamento de Córdoba, Colombia.
La toma de las muestras de suelos fue realizada de acuerdo con lo descrito por Blanco (25) y Brady (26): Se recolectaron 2 muestras (M1 y M2), cada una de 13 submuestras (ICA, 1992). Éstas fueron recolectadas en zigzag, a una profundidad de $0-20 \mathrm{~cm}$, se tomaron $200-300 \mathrm{~g}$ de suelo, se mezclaron, se almacenaron en cartuchos de aluminio y se guardaron en un congelador para análisis posterior.

Obtención de muestras de leche. Diariamente, en las mañanas se tomaron $50 \mathrm{~mL}-100 \mathrm{~mL}$ de leche de un grupo de vacas en ordeño por un periodo de 5 días. Las muestras fueron almacenadas en un frasco colector y guardadas en un congelador $\left(-20^{\circ} \mathrm{C}\right)$ inmediatamente para análisis posterior (9).

Determinación de pesticidas organofosforados. Fueron tomados 7 gramos de muestra de suelo previamente tamizados con un tamaño de partícula $<2 \mathrm{~mm}$ y se sometieron a extracción soxhlet por un periodo de 18 horas, usando como solvente hexano/acetona (Panreac, Estados Unidos) (4:1). Posteriormente, los extractos se concentraron por Kuderna Danish, limpiados en una columna de florisil e inyectados en un equipo de cromatografía de gases GC/FID (Agilent Technologies 4890 D) (27).

Las muestras de leche fueron descongeladas y se tomaron $12 \mathrm{~mL}$ de cada una, las que fueron depositadas en un vial de vidrio, se agregó agua ultra pura y una solución de cloruro de sodio al 20\% para obtener una mejor condición de salting out, el vial fue sellado y dejado por un periodo de $30 \mathrm{~min}$ en equilibrio. Posteriormente, se realizó la extracción de los compuestos organofosforados mediante SPME, introduciendo una fibra de Polidimetilsiloxano - Divinilbenceno (65 $\mu \mathrm{m}$ - PDMS-DVB) en el espacio de cabeza (HS) del vial, este fue puesto en una plancha de calentamiento con agitación magnética por un periodo de 45 minutos a $600 \mathrm{rpm}$ y una temperatura aproximada de $90^{\circ} \mathrm{C}$, después de este tiempo la fibra fue retirada e introducida en un equipo de cromatografía de gases GC/FID y sometida a desorción por un tiempo de 5 minutos a $250^{\circ} \mathrm{C}(8)$.

Las condiciones cromatográficas para la separación e identificación de los compuestos OPs fueron la siguientes: columna capilar HP-5 $(30 \mathrm{~m} * 0.32 \mathrm{~mm} * 0.25 \mu \mathrm{m})$, helio como gas de arratre a un flujo de $1-2 \mathrm{~mL} / \mathrm{min}$, la rampa de temperatura del horno inició en $60^{\circ} \mathrm{C}$ durante 2 minutos, luego se elevó a razón de $15^{\circ} \mathrm{C} / \mathrm{min}$ hasta $160^{\circ} \mathrm{C}$ durante un periodo de 6 minutos y finalmente llevada a una temperatura de $280^{\circ} \mathrm{C}$ a razón de $20^{\circ} \mathrm{C} / \mathrm{min}$; gases de combustión del FID: Hidrogeno/ Aire en proporciones 1:3 respectivamente. El análisis cualitativo y cuantitativo se realizó usando patrones estándar de compuestos organofosforados.

Obtención, aislamiento e identificación de cepas bacterianas. Se llevó a cabo mediante técnicas microbiológicas descritas (28-30), se tomaron $300 \mathrm{~g}$ de suelo de cultivo e impregnado con $20 \mathrm{~mL}$ de una solución estándar de clorpirifos a 200 ppm, se dejó secar y puesto a oscuridad por un periodo de 30 días a una temperatura de $30^{\circ} \mathrm{C}$. Pasado este tiempo el suelo fue tamizado, se tomó $1 \mathrm{~g}$ y adicionado en $9 \mathrm{~mL}$ de agua destilada estéril, esta dilución fue la base para preparación de soluciones sucesivas de 10-1 a 10-4 utilizando como solvente medio mínimo M9 $(6 \mathrm{~g}$ de fosfato ácido de sodio hidratado, $3 \mathrm{~g}$ de fosfato acido de potasio, $4 \mathrm{~g}$ de cloruro de amonio, 0,5 g de cloruro de sodio, 0,25 de sulfato de manganeso heptahidratado, 0,0168 g de cloruro de calcio hidratado) con clorpirifos a 200 ppm como única fuente de carbono, este medio fue incubado por una semana a $36^{\circ} \mathrm{C}$ $\pm 1(30,31)$. Después del tiempo de incubación y que se haya observado una turbidez de 0,5 McFarland, se procedió a tomar 
$100 \mu \mathrm{L}$ de las colonias suspendidas e se incubaron en agar nutritivo mediante una siembra masiva durante una semana a $36^{\circ} \mathrm{C} \pm 1$, una vez comprobado el crecimiento de las colonias, estas fueron aisladas y sembradas en agar nutritivo durante las mismas condiciones de incubación antes mencionadas. Las cepas fueron identificadas mediante pruebas bioquímicas tales como tinción de gram, catalasa, oxidasa y agar sangre, así como también el uso de kits especializados para tal fin como BBL CRYSTALC).

Sometimiento de bacterias identificadas a degradación de OPs. Cada una de las cepas identificadas fueron sembradas en medio mínimo M9 con pesticida organofosforado clorpirifos a 200 ppm como única fuente de carbono y se verificó su crecimiento mediante espectrofotometría UV-VIS por un periodo de 120 horas. Posteriormente los medios fueron sometidos a cromatografía de gases GC/FID antes y después de ser inoculados con las cepas bacterianas para determinar la degradación del clorpirifos por parte de las bacterias aisladas (30). El seguimiento del crecimiento bacteriano y degradación se realizó mediante la medición de un blanco con el fin de observar claramente el potencial de las bacterias en este proceso.

Análisis estadístico. Para el desarrollo de la investigación se empleó un diseño experimental unifactorial, con dos tratamientos (cepas bacterianas) y un blanco (ausencia bacteriana), teniendo como variables de respuesta, el crecimiento bacteriano y el porcentaje de reducción de la concentración de clorpirifos.

Para procesar estadísticamente los datos, primero se tabularon en hojas electrónicas del programa computacional Excel de Microsoft, posteriormente los datos se analizaron mediante el uso del paquete estadístico Prisma 6.0; a partir del cual se identificó el modelo de mejor ajuste, al tipo de crecimiento que presentaron las bacterias, así como también se realizó una comparación del porcentaje de reducción de clorpirifos en los medios experimentales, mediante un análisis de varianza (ANOVA), unifactorial (cepa bacteriana).

\section{RESULTADOS}

Determinación de OPs en muestras de suelo y leche de ganado bovino. El compuesto encontrado en los extractos obtenidos de los suelos fue el Demetón-S-metilsulfón utilizado para el control de ciertos insectos, este insecticida fue detectado en la zona de estudio en concentraciones de 272,9 ppm y 1793,3 ppm.

Por su parte en las muestras de leche, una vez fue expuesta la fibra de $65 \mu \mathrm{m}$ - PDMS-DVB y sometida a desorción en GC/FID, se pudo identificar el compuesto organofosforado Demetón-S-Metilsulfón a una concentración 12,9ppm.

Identificación de bacterias con capacidad degradadora de Ops. Las pruebas bioquímicas de identificación, sugirieron la presencia de dos tipos de bacilos, la cepa 1 fue un bacilo gram negativo (-) y la cepa 2 fue un bacilo gram positivo (+). Bioquímicamente la Cepa 1 fue gamma hemolítica, oxidasa negativa y catalasa positiva; por su parte la Cepa fue gamma hemolítica, oxidasa negativa y catalasa positiva (32).

La Cepa 2 por sus características microscópicas fue identificada en el género Bacillus sp, este género de bacterias se caracteriza y diferencia de las demás bacterias gram positivas por la presencia de esporas y prueba de catalasa negativa (33); mientras que la Cepa 1 por sus características observadas a través de su tinción gram negativa fue sembrada en BBL CRYSTAL para su identificación sugiriendo con un porcentaje de confiabilidad del 98\% la presencia de pantoea agglomerans, un bacilo gram negativo de la familia Enterobacteriaceae, es un tipo de bacterias que se encuentra en diferentes matrices ambientales tales como suelo (34).

Crecimiento y verificación de la capacidad degradadora de las cepas bacterianas. Las colonias de estudio fueron sembradas en medio mínimo M9 con una concentración de clorpirifos de 200 ppm, se incubaron a $36{ }^{\circ} \mathrm{C} \pm 1$ y cada 24 horas fue monitoreado el crecimiento bacteriano midiendo su densidad óptica por medio de un espectrofotómetro UV-VIS a $600 \mathrm{~nm}$. La tabla 1 muestra que las dos cepas bacterianas pueden crecer en este medio selectivo usando como única fuente de carbono el pesticida organofosforado.

Para la verificación de la disminución del compuesto organofosforado por parte de las cepas bacterianas, los medios de cultivo líquidos fueron sometidos a GC/FID en intervalos de 24 horas. Para tal fin se elaboró una curva de calibración del compuesto organofosforado clorpirifos y se procedió a inyectar cada una de las muestras de cada cepa bacteriana y se evaluó la concentración del pesticida presente, a su vez se evaluó un blanco como control negativo para garantizar que la degradación de OPs no sea atribuida a otros factores tales como la temperatura de incubación de las muestras.

Crecimiento bacteriano. El comportamiento del crecimiento bacteriano de las dos cepas, Bacillus sp y Pantoea agglomerans mostró que ambas presentaban un ajuste significativo al modelo exponencial (P-valor < 0.001), con valores del coeficiente de determinación (R2), iguales a 0.94 y 0.87

TABLA 1

Crecimiento de cepas bacterianas.

Tiempo de incubación (Horas)

0

24

48

72

96

120
Blanco Cepa 1

$0,32 \pm 0,002$

$0,318 \pm 0,002$

$0,323 \pm 0,002$

$0,326 \pm 0,002$

$0,326 \pm 0,001$

$0,325 \pm 0,001$
Densidad óptica*

Blanco Cepa 2 Cepa 1

$0,324 \pm 0,001$

$0,317 \pm 0,001$

$0,319 \pm 0,001$

$0,352 \pm 0,001$

$0,325 \pm 0,001$

0,317 $\pm 0,001$

$0,357 \pm 0,001$

$0,326 \pm 0,001$

$0,325 \pm 0,001$

$0,393 \pm 0,001$

0,331 $\pm 0,001$

0,324 $\pm 0,001$

$0,445 \pm 0,002$

$0,363 \pm 0,002$

$0,322 \pm 0,001$

$0,522 \pm 0,001$

$0,389 \pm 0,002$

*Los datos son presentados como densidad óptica \pm error estándar. 
para las cepas Bacillus sp y Pantoea agglomerans respectivamente. Sin embargo, al comparar graficamente las dos cepas, se aprecia que la primera presenta mayor concentración, con respecto a la segunda, es decir que la proliferación del Bacillus sp es mayor que la del p. agglomerans (figura 1).

Degradación de clorpirifos por parte de las cepas bacterianas. Al comparar el porcentaje de reducción del clorpirifos mediante el ANOVA, se pudo comprobar que existen diferencias estadísticamente significativas $(P<<0.05)$, entre los tratamientos (tabla 2); además, mediante las múltiples comparaciones pareadas efectuadas por el método de Tukey, se encontró que la especie Bacillus sp., fue quien tuvo mayor porcentaje de reducción (figura 2).

\section{DISCUSIÓN}

De acuerdo con los resultados obtenidos en los suelos de cultivo, podemos observar dos valores muy diferentes en las concentraciones del compuesto organofosforado demeton-Smetilsulfón, los cuales pueden ser atribuidos a la morfología de la zona de cultivo, la cual mostraba una inclinación, permitiendo escorrentías o transporte de estos compuestos a las zonas más bajas logrando su respectiva acumulación durante el periodo de cultivo, dando como resultado que esta zona más baja presente una concentración más elevada del compuesto organofosforado determinado. Lo relevante es que estos suelos al ser usados como zona de pastoreo de ganado bovino y de futuras siembras se convierten en una posible amenaza desde el punto de vista de la dinámica ambiental de estos compuestos organofosforados ya que podrían encontrarse en las cosechas posteriores y en los productos derivados como carne y leche de los animales ubicados en esas zonas para pastoreo (9), esto último se evidencia en la determinación de la sustancia demetón-S-metilsulfón en la leche de ganado bovino.

La presencia de pesticidas en este tipo de matrices como la leche, cobra importancia debido al creciente uso de estos compuestos que si bien son menos persistentes que sus homólogos organoclorados, poseen ciertas propiedades fisicoquímicas como su variable liposolubilidad que les permite pasar de una matriz a otra llegando a ocasionar desequilibrios desde el punto de vista ambiental y sobre todo a la hora de ser consumidos por el ser humano debido a la toxicidad que estas sustancias poseen $(2,6,13,35,36)$.

A su vez, fue monitoreado el crecimiento por parte de las dos cepas bacterianas obtenidas, a través de la densidad óptica y comparado con un blanco. Se observó que estas bacterias presentan un crecimiento de tipo exponencial, lo

\section{FIGURA 1}

Crecimiento de cepas bacterianas en medio selectivo con OPs.

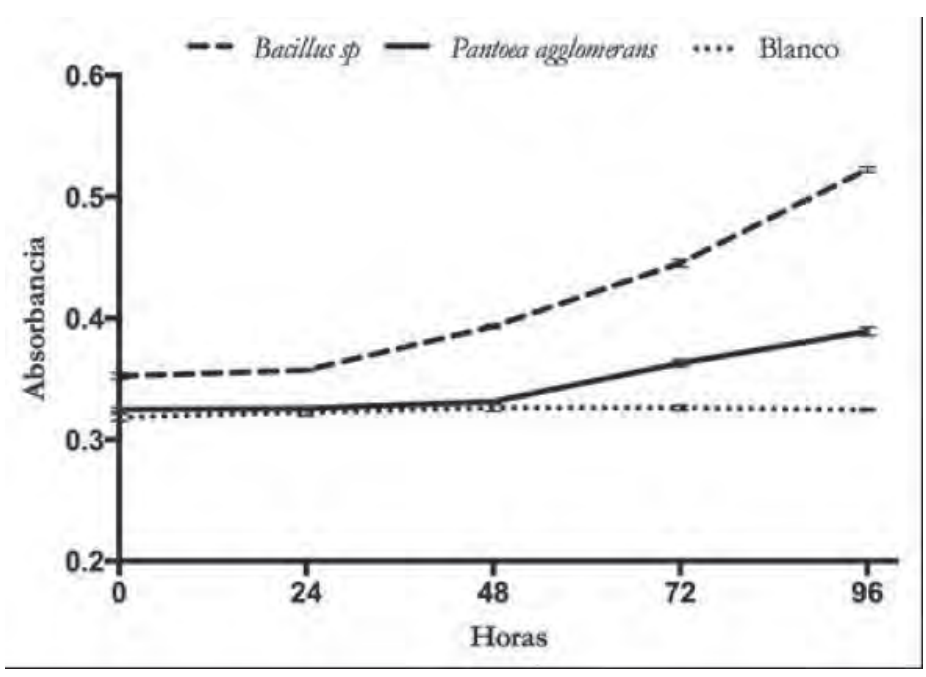

TABLA 2

Análisis de varianza para el porcentaje de reducción de clorpirifos en cada tratamiento, incluido el blanco.

\begin{tabular}{lcccc}
\hline Fuente & Suma de Cuadrados & Gl & Cuadrado Medio & Razón-F \\
Entre grupos & 7782,7 & 2 & 3891,35 & 6829,85 \\
Intra grupos & 3,41854 & 6 & 0,569756 & 0,0000 \\
Total (Corr.) & 7786,12 & 8 & & \\
\hline
\end{tabular}


que confirma que estas cepas con el transcurrir del tiempo utilizan el medio selectivo con el pesticida organofosforado clorpirifos como fuente de carbono para su desarrollo, esto no es nuevo en esta clase de microorganismos ya que diversos trabajos han mostrado comportamientos similares en periodos de tiempos un poco más prolongados, en el que este proceso tuvo una duración de 20 días (37-40).

Al observar la degradación del clorpirifos, notamos que los tratamientos que poseen las cepas bacterianas Bacillus sp y Pantoea agglomerans lograron una mayor reducción con respecto al blanco, se aprecia que transcurrido un tiempo de 24 horas la concentración del pesticida disminuyó de 148,4 ppm hasta 39.34, 45.02 y 134.6 ppm para las cepas Bacillus sp, Pantoea agglomerans y el Blanco respectivamente, lo que equivale a una reducción de $73.50 \%, 69.67 \%$ y $9.28 \%$ del clorpirifos, respectivamente para las cepas mencionadas con anterioridad; denotándose mayor degradación por parte de la primera especie (figura 2). Se puede inferir a partir de la poca disminución del pesticida en el blanco y que este fué detectado durante el periodo del ensayo, que la disminución de la concentración de clorpirifos se debe al proceso metabólico por parte de las cepas bacterianas y no a las condiciones de temperatura presentadas durante la incubación de dichos microorganismos, estudios similares con otro tipo de OPs como el monocrotofós han mostrado que suelos autoclavados tuvieron más persistencia por parte del pesticida, lo que afirma que si bien la temperatura potencia la degradación del pesticida, esta velocidad de degradación no es significativa al compararse con el proceso metabólico.

Los resultados obtenidos tanto para la cepa de Bacillus sp como para Pantoea agglomerans son productos del metabolismo de dichos microorganismos con respecto a este tipo de compuestos ya que para la degradación de pesticidas OPs como para otro tipo de sustancias utilizan enzimas especializadas, que para este caso, es conocida como fosfotriesterasa, la cual puede influir de manera muy significativa en los procesos de biorremediación (41).

Otros estudios han evaluado la degradación de clorpirifos por parte de muchos microorganismos nativos de diferentes suelos y se ha encontrado que la cepa Bacillus sp ha mostrado gran importancia en este proceso, obteniendo porcentajes de degradación hasta $97 \%$ en periodos de 120 horas (42), que comparados con los resultados obtenidos en este estudio, muestran capacidad degradadora por parte de esta especie. Cabe resaltar que el porcentaje de degradación de $73.50 \%$ y $69.67 \%$ por parte de las cepas bacterianas se desarrolló en un periodo de 96 horas y que no se pudo estimar en un rango mayor de tiempo debido a que la concentración de clorpirifos no pudo ser detectada por el equipo de cromatografía de gases, pero la tendencia muestra que el porcentaje de degradación aumenta con el transcurrir del tiempo.

La especie Pantoea agglomerans, conocida también como Enterobacter agglomerans es una especie que obtuvo un resultado muy significativo en cuanto a la degradación del clorpirifos en relación con la especie Bacillus sp, si bien esta última ha sido encontrada en la gran mayoría de suelos y se ha demostrado su capacidad degradadora de sustancias como los OPs (38-40), la especie Pantoea agglomerans ha mostrado su capacidad para otro tipo de sustancias como arsénico y derivados del petróleo $(37,41-43)$. Este es uno de los primeros trabajos en el que se evidencia la capacidad degradadora de las bacterias anteriormente mencionadas para compuestos de tipo organofosforado, utilizando como base el hecho de que esta clase de microorganismos utiliza enzimas especializadas para degradarlos.

\section{CONCLUSIÓN}

La metodología de HS-SPME/GC-FID permitió la separación e identificación de un plaguicida organofosforado (demetón-S-metilsulfón) en suelos y leche de vaca ganado, mostrando que es una técnica confiable para la identificación de estas sustancias en este tipo de matrices, y a su vez eviden-

\section{FIGURA 2}

Capacidad degradadora de cepas bacterianas.

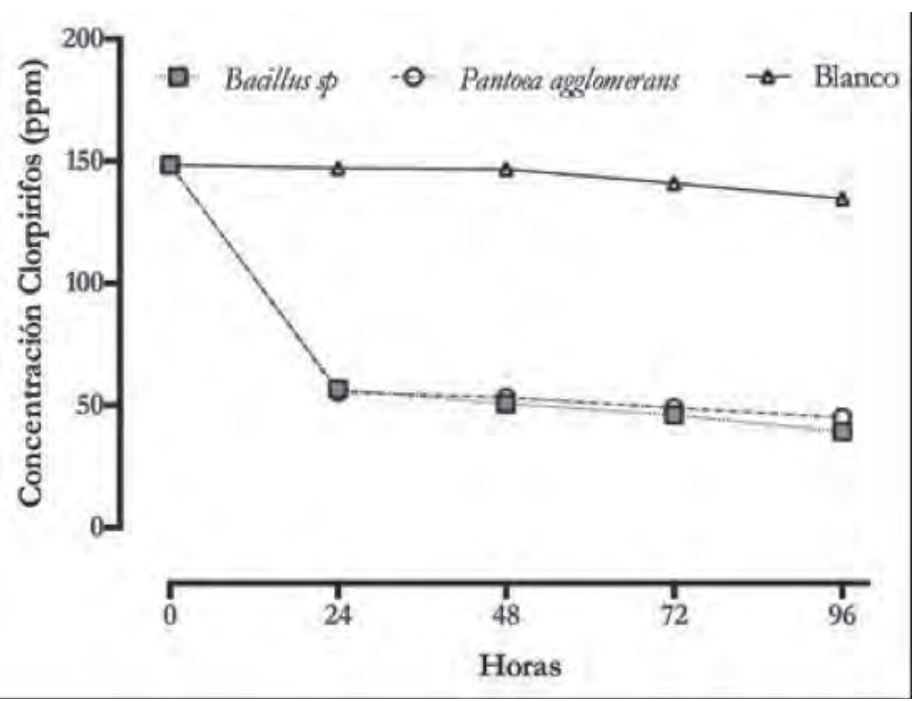


ciando el paso del pesticida en mención del suelo de cultivo a la leche de ganado bovino por medio de su ruta metabólica, lo que hace inherente la búsqueda de técnicas de recuperación de suelos contaminados por OPs, en este caso, en el aislamiento de microorganismos capaces de degradarlos

En los suelos de cultivo se detectó la presencia de cepas bacterianas con capacidad degradadora de pesticidas organofosforados. Estos microorganismos fueron capaces de desarrollarse en medios de cultivo con presencia de clorpirifos en concentraciones de 200 ppm. Los microorganismos aislados fueron identificados por medio de sus características morfológicas y bioquímicas como Bacillus sp, un bacilo gram positivo perteneciente a la familia Bacillaceae, y pantoea agglomerans, un bacilo gram negativo perteneciente a la familia Enterobacteriaceae. Por lo tanto, podemos concluir que estos microorganismos pueden ser utilizados como alternativas de solución para la recuperación de suelos contaminados por OP's, lo cual podría evitar riesgos potenciales a las especies que se encuentran expuestas a esta clase de contaminantes.

\section{RESUMEN}

El incremento en el uso de pesticidas organofosforados en las prácticas agrícolas a través de los últimos años, ha generado una serie de problemas ambientales. Estos compuestos tienden a bioacumularse a través de las cadenas tróficas presentando altos niveles de toxicidad desencadenando potenciales riesgos para la salud de las especies que son expuestas a este tipo de sustancias. En esta investigación se usaron los métodos de extracción soxhlet y micro extracción en fase sólida en espacio de cabeza (HS-SPME) para la extracción de pesticidas organofosforados en suelos de cultivo y leche de ganado bovino, respectivamente. Se determinó la presencia de demetón-Smetilsulfón en concentraciones entre 272.9 y 1793.3 ppm en los suelos de cultivo y 12.9 ppm en leche de vaca. Se aislaron bacterias nativas de suelo con capacidad degradadora de estos pesticidas, Bacillus sp y Pantoea agglomerans, obteniéndose resultados de degradación del compuesto organofosforado, clorpirifos de $73.5 \%$ y $68.67 \%$, respectivamente, evidenciando que estos microorganismos son una posible solución para el mejoramiento de suelos contaminados por esta clase de pesticidas.

Palabras clave: Bacillus sp, pantoea agglomerans, HS$S P M E$, cClorpirifos, demetón $-S$ - metilsulfón, leche de vaca.

Agradecimientos: Agradecemos a la Universidad de Cartagena y a su Vicerrectoría de Investigaciones por la financiación de este proyecto, al grupo de Investigaciones Agroquímicas (GIA) de la Facultad de Ciencias Exactas y Naturales por todo el apoyo brindado durante esta investigación, y a los Señores: Orlando De La Rosa y Juan Carlos Valdelamar, por su valiosa colaboración en este proyecto.

Conflicto de interés: Los autores de este artículo declaran que no tienen ningún conflicto de interés.

\section{BIBLIOGRAFÍA}

1. FAO/OMS. Garantía de la inocuidad y calidad de los alimentos: directrices para el fortalecimiento de los sistemas nacionales de control de los alimentos. Estudio FAO Alimentación Y Nutrición 76. Roma, Italia, 2003, p 91. En: http://www.fao.org/docrep/006/y8705s/y8705s00.htm. Revisado en noviembre de 2013.

2. Selvi C, Paramasivam M, Rajathi DS, Chandrasekaran S. Multiresidue Analysis of Organochlorine Pesticides in Milk,
Egg and Meat by GC-ECD and Confirmation by GC-MS. Bull Environ Contam Toxicol. 2012; 89 (5): 1051-56.

3. Bayat S, Sari AE, Bahramifar N, Younesi H, Dahmarde Behrooz R. Survey of organochlorine pesticides and polychlorinated biphenyls in commercial pasteurized milk in Iran. Environ Monit Assess. 2011; 175:469-74.

4. De Arco D, Jaramillo BE. Evaluación de Plaguicidas Organoclorados Por HS-SPME - GC/ECD En Leche Pasteurizada Comercializada en la Ciudad de Cartagena (Colombia). Rev Bio Agro. 2011; 9 (2): 41 - 8.

5. Lacorte S, Guillamon M. Validation of a pressurized solvent extraction and GC-NCI-MS method for the low-level determination of 40 polybrominated diphenyl ethers in mothers' milk. Chemosphere 2008; 73: 70-5.

6. Gazzotti $T$, Sticca P, Zironi E, Lugoboni B, Serraino A, Pagliuca G. Determination of 15 Organophosphorus Pesticides in Italian Raw Milk. Bull Environ Contam Toxicol. 2009; 82:251-4.

7. Pagliuca G, Gazzotti T, Zironi E, Pavoncelli N, Rosmini R. Proposal of an Analytical Method for Determination of Residues of Organophosphorus Pesticides in Milk by GLCNPD. Vet Res Commun. 2004; 28: 257-9.

8. Rodriguez F, Mesquita $P$, De Oliveira L, De Oliveira F, Filho A, Pereira P, De Andrade J. Development of a headspace solid-phase microextraction/gas chromatography-mass spectrometry method for determination of organophosphorus pesticide residues in cow milk. Microchem J. 2011; 98: 56-61.

9. Santaeufemia M, Melgar MJ, Cepeda A, García MA. Estudio de la contaminación por plaguicidas organofosforados y triazinas en leche procedente de diversas rutas de recogida. Rev Toxicol. 2006; 23: 7-10.

10. Yang $L$, et al. Determination of 49 Organophosphorus Pesticide Residues and Their Metabolites in Fish, Egg, and Milk by Dual Gas Chromatography-Dual Pulse Flame Photometric Detection with Gel Permeation Chromatography Cleanup. J Agric Food Chem. 2012; 60: 1906-13.

11. Cardeal Z de L, Dias Paes CM. Analysis of organophosphorus pesticides in whole milk by solid phase microextraction gas chromatography method. J Environ Sci Health B. 2006; 41(4): 369-75.

12. Martínez $J$, Plaza P, Romero R, Garrido A. Determination of pesticide transformation products: $A$ review of extraction and detection methods. J Chromatogr A. 2009; 1216: 6767-88.

13. Tsiplakou E, Anagnostopoulos CJ, Liapis K, Haroutounian SA, Zervas G. Pesticides residues in milks and feedstuff of farm animals drawn from Greece. Chemosphere 2010; 80 (5): 504-12.

14. Hua $Y, X u D, Q i J$, Huai X. Enhanced degradation of five organophosphorus pesticides in skimmed milk by lactic acid bacteria and its potential relationship with phophatase production. Food Chem. 2014; 164: 173-8.

15. Eddleston M, Street J, Thomson A, Kings T., Williams N. A role for solvents in the toxicity of agricultural organophosphorus pesticides. Toxicology 2012; 294(2-3): 94-103.

16. Janusz Pawliszyn (Editor). Soxhlet extraction and new developments such as soxtec. En: Comprehensive Sampling and Sample Preparation: Analytical Techniques for Scientists. Academic Press, 2012.

17. LeDoux M. Analytical methods applied to the determination of pesticide residues in foods of animal origin. A review of the past two decades Review. J Chromatogr A. 2001; 1218: 1021-36. 
18. Abdulra'uf $L B$, Tan GH. Multivariate study of parameters in the determination of pesticide residues in apple by headspace solid phase microextraction coupled to gas chromatography-mass spectrometry using experimental factorial design. Food Chem. 2013; 141 (4): 4344-8.

19. Garrido Frenich A, Martínez Vidal JL, Cruz Sicilia AD, González Rodríguez MJ, Plaza Bolaños P. Multiresidue analysis of organochlorine and organophosphorus pesticides in muscle of chicken, pork and lamb by gas chromatography-triple quadrupole mass spectrometry. Anal Chim Acta 2006; 558 (1-2): 42-52.

20. Sang ZY, Wang YT, Tsoi YK, Leung KS CODEX-compliant eleven organophosphorus pesticides screening in multiple commodities using headspace-solid phase microextractiongas chromatography-mass spectrometry. Food Chem. 2013; 136 (2):710-7.

21. Fernández $M$, Llompart $M$, Lamas $J P$, Lores $M$, Garcia $M$, et al. Development of a solid-phase microextraction gas chromatographywith microelectron-capture detection method for a multiresidue analysis of pesticides in bovine milk. Anal Chim Acta 2008; 617(1-2): 37-50.

22. www.sanbernardodelviento-cordoba.gov.co. Consultado Abril 52014.

23. Vidali, M. Bioremediation. An overview. Pure Appl Chem. 2001; 73(7): 1163-72.

24. Vargas $P$, Cuéllar $R$, Dussán J. Biorremediacion de residuos del petroleo. Hipótesis 2004; 4:44-9.

25. Blanco J. Manejo Integral de Suelos con énfasis en el Cultivo del Arroz. Editorial Pronatia. Colombia. 2003.

26. Brady N, Weil R. The nature and properties of soils. Editorial Prentice Hall, NJ, USA, 1999.

27. Kuranchie-Mensah H, Manukure S, Maud L, Blankson S, Osei $A$, et al. Determination of organochlorine pesticides residue in sediment a water from the Densu river basin, Ghana. Chemosphere 2012; 86 (3): 286-92.

28. Boonchan S, Britz M, Stanley G Degradation and mineralization of high-molecularweight polycyclic aromatic hydrocarbons by defined fungal-bacterial cocultures. Appl Environ Microbiol. 2000; 66:1007-19.

29. Aquiahuatl M, Pérez M Manual de Prácticas del Laboratorio de Microbiología: Pruebas de diferenciación Bioquímica. Editorial Casa Abierta al Tiempo, Iztapalapa, México, 2004.

30. Fernández $L$, Zalba $P$, Gómez M, Sagardoy M. Bacterias solubizadoras de fosfato inorgánico aisladas de suelos de la región sojera. Rev Cienc Suelo 2005; 23:31-37.

31. Elbing E, Brent R. Media preparation and bacteriological tools. Curr Protoc Mol Biol 2002; 57:111-7.

32. Konneman E. Konneman's color atlas and textbook of diagnostic microbiology. Lippincott Williams \& Wilkins, Baltimore, USA, 2001.

33. Forbes $B$, Sahm D, Weissfeld A. Bailey \& Scott: Diagnóstico Microbiológico. Ed Panamericana. Buenos Aires, Argentina, p 281, 2009.

34. Feng $Y$, Shen $D$, Song $W$. Rice endophyte Pantoea agglomerans YS19 promotes host plant growth and affects allocations of host photosynthates. J Appl Microbiol. 2006; 100 (5):938-45.

35. Lein P, Bonner M, Farahat F, Olson J, Rohlman D, et al. Experimental strategy for translational studies of organophosphorus pesticides neurotoxicity based on real-world occupational exposures to chlorpyrifos. Neuro Toxicol. 2012; 33(4): 660-8.

36. Matthaios $P$, Kavvalakis $A$, Tsatsakis $M$. the atlas of dialkylphosphates; assessment of cumulative human organophosphorus pesticides' exposure. J Forensic Sci Intern. 2012; 218 (1-3):111-22.

37. Acuña A, Pucci G, Morales M, Pucci O. Biodegradación de petróleo y sus derivados por la comunidad bacteriana en un suelo de La Patagonia Argentina. Rev Soc Ven Microbiol. 2010; 30(2): 29-36.

38. Pino N, Peñuela P. Simultaneous degradation of the pesticides methyl parathion and chlorpyrifos by isolated bacterial consortium from a contaminated site. Intern Biodet Biodegrad. 2011; 65:827-31.

39. Ohshiro K, Kakuta T, Sakai T, Hirota H, Hoshino T, et al. Biodegradation of organophosphorus insecticides by bacteria isolated from turf green soil. J Ferment Bioeng. 1996; 82(3): $299-305$.

40. Cycón M, Zmijowska A, Wójcik M, Piotrowska Z. Biodegradation and bioremediation potential of diazinon-degrading Serratia marcescens to remove other organophosphorus pesticides from soils. J Environ Manage. 2013; 117: 7-16.

41. Khleifat K. Biodegradation of linear alkylbenzene sulfonate by a two member facultative anaerobic bacterial consortium. Enzyme Microb Tech. 2006; 39(5):1030-35.

42. Bhatia S, Sharma DK. Biodesulfurization of dibenzothiophene, its alkylated derivatives and crude oil by a new isolated strain pantoea agglomerans D23W3. Biochem Eng J. 2010; 50(3):104-9.

43. Bentley R, Chasteen TG. Microbial Methylation of Metalloids: Arsenic, Antimony, and Bismuth. Microbiol Mol Biol Rev. 2002; 66(2): 250-71. 